\title{
ANALISIS KESTABILAN LERENG PADA RUAS JALAN NIMBONTONG- TAJA-LEREH DI KM 123+700
}

\author{
Alfian Adie Chandra \\ Universitas Cenderawasih (UNCEN) Papua, Indonesia \\ Email: alfiansipiluncen@gmail.com
}

\begin{abstract}
Abstrak
Topografi di Papua umumnya merupakan daerah yang terdiri atas gunung dan lembah yang mempunyai kemiringan lereng beragam. Sarana transportasinyapun sedemikian rupa direncanakan sehingga harus melalui lereng tersebut. Salah satunya yaitu pada ruas jalan Nimbontong-Taja-Lereh. Tujuan dari penelitian ini adalah dapat mengetahui faktor keamanan lereng dan mencari desain penanggulangan longsoran berdasarkan faktor keamanan lereng yang diperoleh dari analisis kestabilan lereng pada ruas jalan Nimbontong-Taja-Lereh di Km 123+700. Metode penelitian yang dipakai dalam penulisan ini adalah dengan cara mengumpulkan data yang berhubungan dengan perhitungan yaitu topografi dan parameter tanah. Teknik pengumpulan data menggunakan data primer dan sekunder. Data primer yaitu data yang diperoleh secara langsung di lapangan dengan survey lokasi, sedangkan data sekunder yaitu data yang diperoleh dari studi literatur/ sumber penelitian seperti instansi pemerintah, dan swasta. Pada ruas jalan tersebut dilakukan pemotongan lereng agar jalan yang dibuat aman dan nyaman untuk dilalui para pengendara. Namun pada beberapa titik terjadi penurunan permukaan badan jalan. Oleh karena itu perlu dilakukan analisis kestabilan lereng agar dapat mengidentifikasi penyebab longsor tersebut. Analisis stabilitas lereng pada ruas jalan Nimbontong-Taja-Lereh menggunakan program bantu GeoSlope 2007. Dari analisis yang telah dilakukan, dengan kondisi diberi beban jalan dan tekanan air pori maka dapat diambil kesimpulan bahwa lereng pada ruas jalan Nimbotong-Taja-Lereh Km 123+700 termasuk lereng yang kritis terhadap longsor karena faktor kemanan lereng berada dibawah 1,07. Faktor penyebab longsor yang menentukan adalah akibat tekanan air pori karena setelah dilakukan analisis menggunakan beban jalan sebesar $12 \mathrm{Kpa}$, hasil analisis menunjukkan factor keamanan masih diatas 1,07.
\end{abstract}

Kata Kunci: stabilitas; lereng; geoslope

\section{Abstract}

Topography in Papua is generally an area consisting of mountains and valleys that have a diverse slope. The means of transportation are so planned that they have to go through the slopes. One of them is on the Nimbontong-Taja-Lereh road. The purpose of this study was to be able to find out the slope safety factors and look for avalanche management designs based on slope safety factors obtained from the slope stability analysis on the Nimbontong - Taja - Lereh road at Km $123+700$. The research method used in this writing is to collect data related to calculations, namely topography and soil parameters. Data collection techniques use primary 
and secondary data. Primary data is data obtained directly in the field with location surveys, while secondary data is data obtained from literature studies / research sources such as government agencies, and private. On the road is done cutting the slopes so that the road is made safe and comfortable for motorists to pass. But at some point there is a decrease in the surface of the road body. Therefore, it is necessary to analyze the stability of the slope in order to identify the cause of the landslide. Analysis of slope stability on the Nimbontong - Taja-Lereh road using the GeoSlope 2007 assist program. From the analysis that has been done, with the condition of the road load and pore water pressure, it can be concluded that the slopes on the Nimbotong-Taja-Lereh Km 123+700 road including slopes that are critical to the slope's safety landslide factor are below 1.07. The determining cause of landslides is due to pore water pressure because after analysis using a road load of $12 \mathrm{Kpa}$, the results of the analysis showed the safety factor was still above 1.07.

Keywords: stability; slope; geoslope

\section{Pendahuluan}

Negara Indonesia termasuk salah satu negara yang berpotensi terjadinya bencana alam. Secara umum bencana alam merupakan suatu peristiwa atau rangkaian peristiwa yang terjadi diakibatkan oleh alam yang dapat mengancam dan mengganggu kehidupan dan penghidupan masyarakat, serta mengakibatkan kerusakan lingkungan yang disebabkan oleh faktor alam dan faktor non alam dan mengakibatkan sebagian besar merenggut korban jiwa (Putri, 2019).

Tanah longsor merupakan bencana alam geologi yang diakibatkan oleh gejala alam geologi maupun tindakan manusia dalam mengelola lahan. Dampak dari bencana ini sangat merugikan, baik dari segi lingkungan maupun sosial ekonomi (Suwaryo \& Yuwono, 2017).

Longsoran yaitu proses perpindahan atau pergerakan massa batuan, debris (campuran butiran batu dan tanah yang tidak mengandung air maupun yang mengandung air), dan tanah kearah lereng bawah. Perpindahan ini dapat disebabkan oleh kondisi geologi yang kurang menguntungkan, fenomena geomorfologi gaya - gaya fisik alamiah atau akibat ulah manusia. Keruntuhan lereng adalah suatu proses pergerakan dan perpindahan massa tanah atau batuan yang dapat terjadi dengan variasi kecepatan dari sangat lambat sampai sangat cepat dan tidak terkait banyak dengan kondisi geologi lokal. Keruntuhan bersifat lokal atau skala kecil dan umumnya terjadi pada lereng galian atau timbunan yang dibuat manusia (Noor, 2014).

Gerakan tanah/ longsoran adalah perpindahan massa tanah/ batuan pada arah tegak, mendatar atau miring dari kedudukan semula. Dalam definisi ini termasuk juga deformasi lambat atau jangka panjang dari suatu lereng yang biasa disebut rayapan (creep). Pada dasarnya kunci utama gerakan tanah adalah kuat geser tanah yang dapat terjadi (Karapa, Harianto, Muhiddin, \& Irmawaty, 2020):

a) Tak terdrainase,

b) Efektif untuk beberapa kasus pembebanan, 
c) Meningkat sejalan peningkatan konsolidasi (sejalan dengan waktu) atau dengan kedalaman,

d) Berkurang dengan meningkatnya kejenuhan air (sejalan dengan waktu) atau terbentuknya tekanan pori yang berlebih atau terjadi peningkatan air tanah.

Zona berpotensi longsor adalah daerah/kawasan yang rawan terhadap bencana longsor dengan kondisi terrain dan kondisi geologi yang sangat peka terhadap gangguan luar, baik yang bersifat alami maupun aktifitas manusia sebagai faktor pemicu gerakan tanah, sehingga berpotensi terjadinya longsor (Haribulan, Gosal, \& Karongkong, 2019). Berdasarkan hidrogeomorfologinya dibedakan menjadi tiga tipe zona yang digambarkan sebagai berikut:

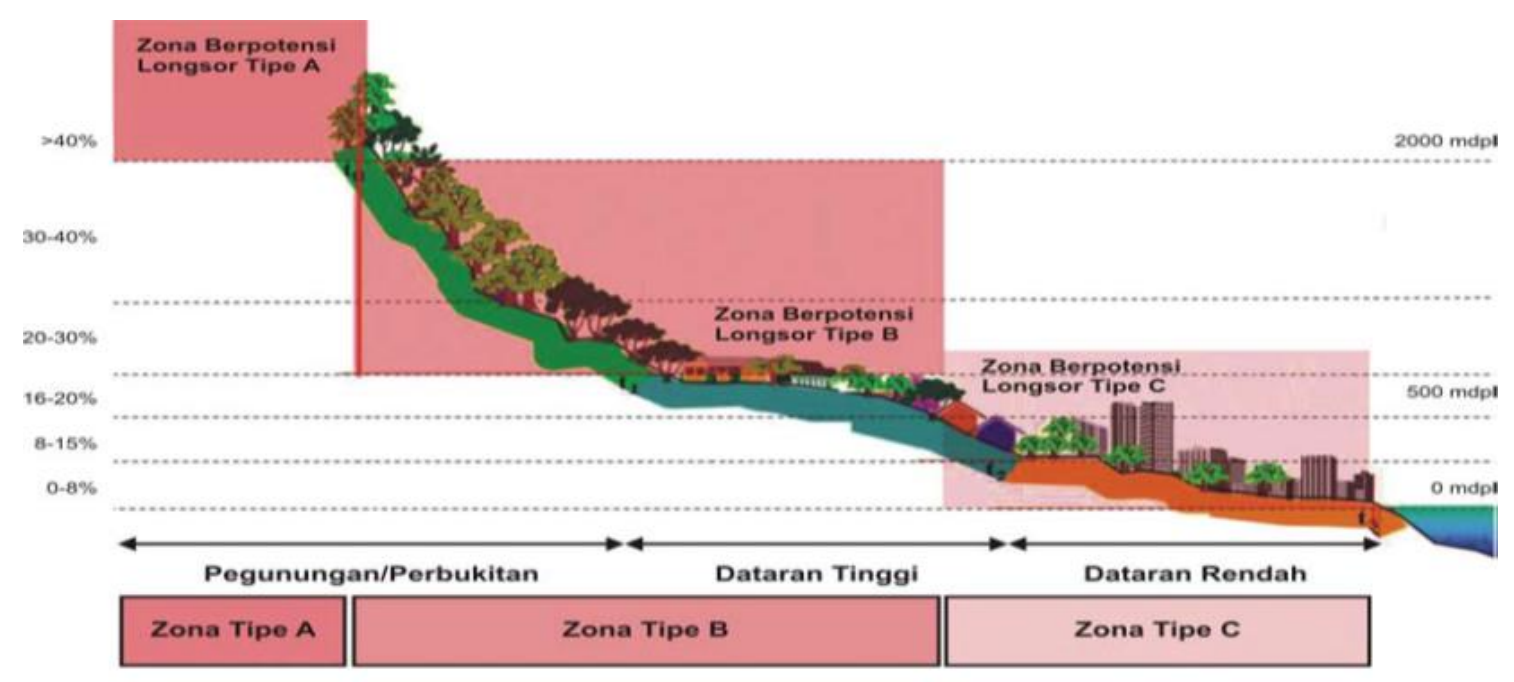

Gambar 1

Zona Berpotensi Longsor

Zona tipe A merupakan Zona berpotensi longsor pada daerah lereng gunung, lereng pegunungan, lereng bukit, lereng perbukitan, dan tebing sungai dengan kemiringan lereng lebih dari 40\%, dengan ketinggian di atas 2000 meter di atas permukaan laut (Sinarta, 2013).

Zona tipe B merupakan daerah kaki bukit, kaki perbukitan, kaki gunung, kaki pegunungan, dan tebing sungai atau lembah sungai dengan kemiringan lereng $21 \%$ hingga 40\% dengan ketinggian 500 meter sampai dengan 2000 (Sinarta, 2013).

Zona tipe $\mathrm{C}$ merupakan daerah kaki bukit, kaki perbukitan, kaki gunung, kaki pegunungan, dan tebing sungai atau lembah sungai dengan kemiringan lereng $0 \%$ hingga 20\% dengan ketinggian 0 sampai dengan 500 meter di atas permukaan laut (Kamil, Poli, \& Karongkong, 2014).

Gerakan tanah dikelompokkan menurut klasifikasi Highway Research Board 1958 dan 1978. Kriteria yang digunakan dalam pengelompokan ini pertama adalah tipe gerakan tanah dan kedua jenis materialnya. Tipe gerakan tanah dibagi menjadi lima kelompok utama yaitu: runtuhan, jungkiran, longsoran, penyebaran lateral dan aliran. 
Kelompok keenam adalah majemuk yaitu kombinasi dua atau lebih tipe gerakan tersebut (Muhammad, 2012).

Kriteria peninjauan untuk penanggulangan keruntuhan lereng meliputi faktor keamanan dan pembebanan. Pembebanan yang diperhitungan dalam peninjauan adalah beban lalu lintas dan beban gempa. Beban lalu lintas ditambahkan pada seluruh lebar permukaan jalan sedangkan besarnya ditentukan berdasarkan kelas jalan berdasarkan tabel berikut (Akbari \& Jaya, 2019):

Tabel 1

Beban Lalu Lintas

\begin{tabular}{ccc}
\hline Kelas Jalan & $\begin{array}{c}\text { Beban Lalu } \\
\text { Lintas (kPa) }\end{array}$ & $\begin{array}{c}\text { Beban di luar } \\
\text { jalan }(\mathbf{k P a})\end{array}$ \\
\hline I & 15 & 10 \\
\hline II & 12 & 10 \\
\hline III & 12 & 10 \\
\hline III & 12 & 10 \\
\hline
\end{tabular}

Pengaruh beban gempa diikutsertakan jika keruntuhan lereng berada pada area bangunan dengan kepentingan yang strategis. Percepatan gempa diperoleh dengan menghubungkan zona gempa dengan tipe tanahnya serta frekuensi dasar (fundamental frequency) bangunan. Dalam hal ini, beban siklis yang ditimbulkan oleh beban gempa akan mengurangi kuat geser tanah residual.

Tingkat kestabilan lereng (faktor keamanan FS) terhadap longsoran menurut Bowles disebutkan bahwa lereng termasuk labil bila FS $<1,07$; lereng kritis 1,07 < FS < 1,25; lereng stabil FS > 1,25 (Pradhana, 2018).

Secara umum faktor keamanan suatu lereng merupakan perbandingan nilai ratarata kuat geser tanah/ batuan di sepanjang bidang keruntuhan kritisnya terhadap beban yang diterima lereng di sepanjang bidang keruntuhannya (Dewantanu \& Taufiq, 2012). Terkait dengan analisis kestabilan lereng perlu dimasukan faktor keamanan yang mengacu pada standar, seperti yang disajikan pada tabel berikut:

Tabel 2

Faktor Keamanan Lereng

\begin{tabular}{llcccc}
\hline \multirow{2}{*}{ Risiko } & \multirow{2}{*}{ Kondisi Beban } & \multicolumn{3}{c}{ Parameter Kuat Geser } \\
\cline { 3 - 6 } & & Teliti & $\begin{array}{c}\text { Kurang } \\
\text { Teliti }\end{array}$ & Teliti & $\begin{array}{c}\text { Kurang } \\
\text { Teliti }\end{array}$ \\
\cline { 3 - 6 } Tinggi & Dengan Gempa & 1,50 & 1,75 & 1,35 & 1,50 \\
\cline { 2 - 6 } & Tanpa Gempa & 1,80 & 2,00 & 1,60 & 1,80 \\
\hline \multirow{2}{*}{ Menengah } & Dengan Gempa & 1,30 & 1,60 & 1,20 & 1,40 \\
\cline { 2 - 6 } & Tanpa Gempa & 1,50 & 1,80 & 1,35 & 1,50 \\
\hline \multirow{2}{*}{ Rendah } & Dengan Gempa & 1,10 & 1,25 & 1,00 & 1,10 \\
\cline { 2 - 6 } & Tanpa Gempa & 1,25 & 1,40 & 1,10 & 1,20 \\
\hline
\end{tabular}


Secara umum tahapan analisis kestabilan lereng adalah evaluasi dan interpretasi parameter hasil investigasi, penentuan stratifikasi lereng, penentuan tipe bidang gelincir dan analisis, serta analisis stabilitas kondisi lereng dengan dan tanpa penanganan.

Evaluasi dan interpretasi parameter menjelaskan evaluasi kondisi detail topografi, geologi, kekuatan geser, kondisi muka air dan beban-beban eksternal yang dibutuhkan untuk analisis stabilitas lereng.

Stratifikasi penampang lereng adalah suatu penampang yang menunjukkan urutan lapisan tanah/ batuan sepanjang yang dikehendaki dari muka tanah sampai batas kedalaman penyelidikan berdasarkan jenis, sifat fisik dan teknik lapisan tanah/ batuan. Penampang ini dihasilkan dari korelasi lapisan yang didapat dari beberapa penyelidikan berdasarkan jenis, sifat fisik dan teknik lapisan tanah/ batuan. Penampang ini dihasilkan dari korelasi lapisan yang didapat dari beberapa penyelidikan pemboran mesin atau pemboran tangan. Gambaran dan bentuk lapisan tanah hasil korelasi dari titik - titik pemboran, sangat ditentukan oleh kondisi geologi setempat, jarak titik penyelidikan, metode penyelidikan, cara dan kecermatan pelaksanaan penyelidikan. Stratifikasi penampang lereng dibuat pada sepanjang as keruntuhan lereng atau penampang lain yang dikehendaki dengan menggunakan peta geoteknik, peta topografi dan profil bor (Dewantanu \& Taufiq, 2012).

Limit Equilibrium Method adalah metode yang menggunakan prinsip kesetimbangan gaya. Metoda analisis ini pertama-tama mengasumsikan bidang kelongsoran yang dapat terjadi (Aprilia, Muslim, Zakaria, \& Tedy, 2019). Terdapat dua asumsi bidang kelongsoran yaitu: bidang kelongsoran berbentuk circular dan bidang kelongsoran yang diasumsikan berbentuk non-circular (bisa juga planar). Perhitungan dilakukan dengan membagibagi tanah yang berada dalam bidang longsor dalam irisanirisan. karena itu metoda ini dikenal juga dengan nama metoda irisan (method of slice). Dalam LEM ini faktor keamanan, SF, pada prinsipnya dihitung dari perbandingan antara kuat geser tanah, $\tau_{f}$ dengan gaya dorong, $\tau$, atau perbandingan antara momen tahan, RM, terhadap momen dorong, DM, sebagaimana ditunjukkan dalam persamaan (Sadikin \& Komarudin, 2018).

$$
S F=\frac{\tau_{f}}{\tau} \text { atau } S F=\frac{R M}{D M}
$$

(Analisa Stabilitas Lereng Limit Equilibrium Vs Finite Element Method, Hatti - Pit Xvi 2012, 4 - 5 Dec 2012, Hotel Borobudur, Jakarta)

Pada cara Fellenius semua gaya antar irisan diabaikan dan hanya memperhitungkan kesetimbangan momen.

Cara ini dapat digunakan pada lereng-lereng dengan kondisi isotropis, non isotropis dan berlapis-lapis. Massa tanah yang bergerak diandaikan terdiri dari atas beberapa elemen vertikal. Lebar elemen dapat diambil tidak sama dan sedemikian sehingga lengkung busur di dasar elemen dapat dianggap garis lurus (Sartika \& Yakin, 2017). Berat total tanah/ batuan pada suatu elemen (W,) termasuk beban Iuar yang 
bekerja pada permukaan lereng $\mathrm{Wt}$, diuraikan dalam komponen tegak lurus dan tangensial pada dasar elemen. Dengan cara ini, pengaruh gaya $\mathrm{T}$ dan E yang bekerja disamping elemen diabaikan. Faktor keamanan adalah perbandingan momen penahan longsor dengan penyebab Iongsor. Pada gambar momen tahanan geser pada bidang Iongsor adalah :

Mpenahan $=$ R. $r$

Dimana: $\mathrm{R}=$ gaya geser

$\mathrm{r}=$ jari-jari bidang longsor

Tahanan geser pada dasar tiap elemen adalah :

$\mathrm{R}=\mathrm{S} \cdot \mathrm{b}=\mathrm{b}\left(\mathrm{c}^{\prime}+\sigma \tan \phi^{\prime}\right) ; \quad \sigma=\frac{\mathrm{W}_{\mathrm{t}} \cos \alpha}{\mathrm{b}}$

Momen penahan yang ada sebesar :

$\mathrm{M}_{\text {penahan }}=\mathrm{r}\left(\mathrm{c}^{\prime} \mathrm{b}+\mathrm{W}_{\mathrm{t}} \cos \alpha \tan \phi^{\prime}\right)$

Komponen tangensial $\mathrm{Wt}$, bekerja sebagai penyebab Iongsoran yang menimbulkan momen penyebab sebesar:

$\mathrm{M}_{\text {penyebab }}=\left(\mathrm{W}_{\mathrm{t}} \sin \alpha\right) \cdot \mathrm{r}$

Faktor keamanan lereng menjadi:

$\mathrm{FK}=\frac{\Sigma\left(\mathrm{c}^{\prime} \mathrm{b}+\mathrm{W}_{\mathrm{t}} \cos \alpha \tan \phi^{\prime}\right)}{\sum \mathrm{W}_{\mathrm{t}} \sin \alpha}$

Jika lereng terendam air atau jika muka air tanah diatas kaki lereng, maka tekanan air pori akan bekerja pada dasar elemen yang ada dibawah air tersebut. Dalam hal ini tahanan geser harus diperhitungkan yang efektif, sedangkan gaya penyebabnya tetap diperhitungkan secara total, sehingga rumus menjadi:

$$
\mathrm{FK}=\frac{\Sigma\left[\mathrm{c}^{\prime} \mathrm{b}+\left(\mathrm{W}_{\mathrm{t}} \cos \alpha-\mathrm{u} \mathrm{b}\right) \tan \phi^{\prime}\right]}{\Sigma \mathrm{W}_{\mathrm{t}} \sin \alpha}
$$

Dimana: $\mathrm{u}=$ tegangan air pori di dasar bidang longsoran. 


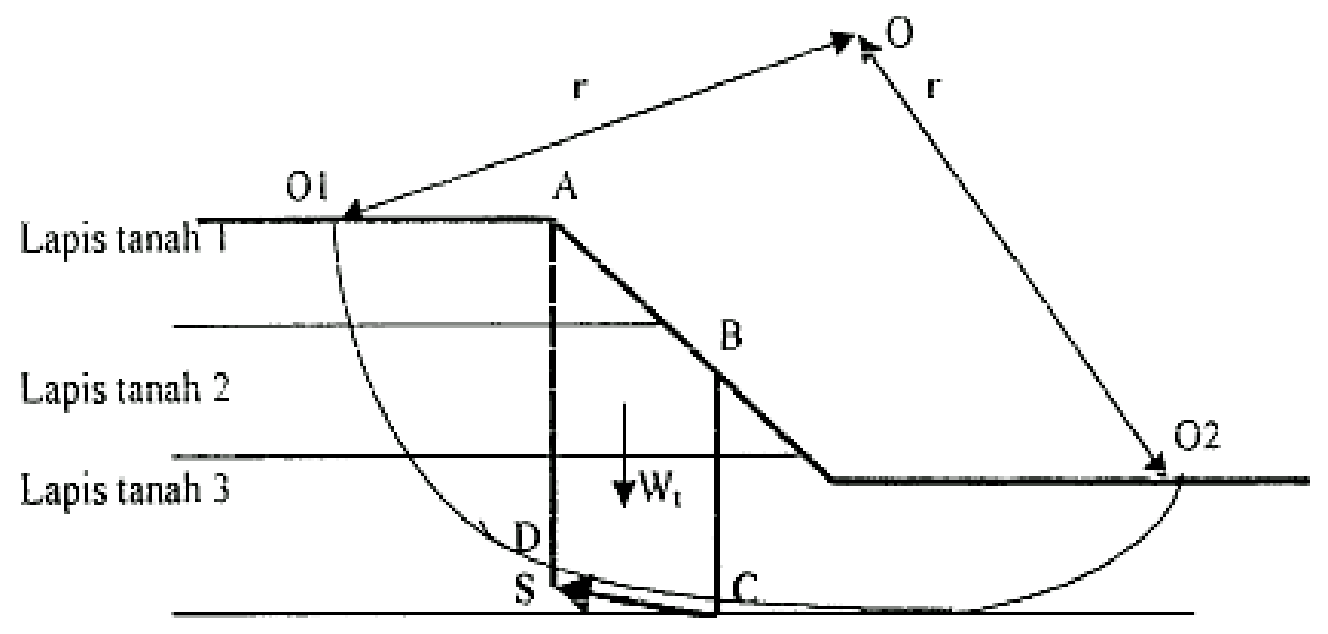

Gambar 2

Penentuan bidang gelincir

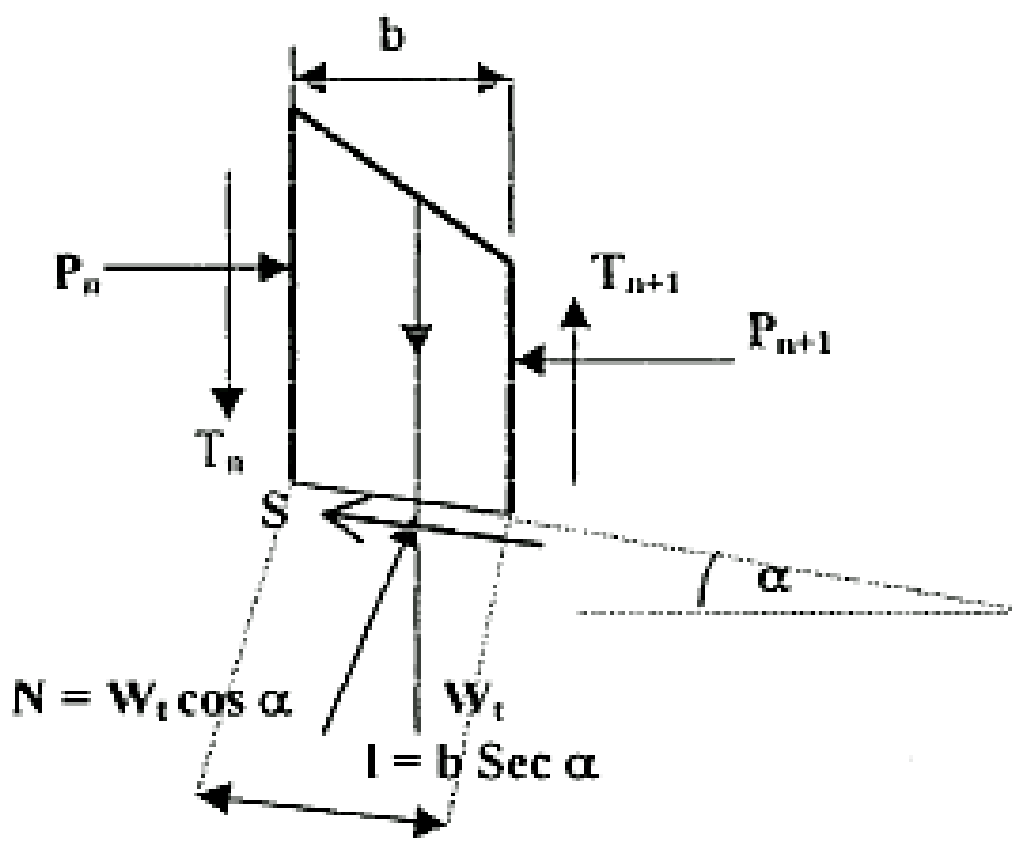

Gambar 3

Gaya-gaya yang bekerja pada irisan tunggal

Dengan:

Wt = berat tanah irisan

b = lebar irisan arah dasar bidang longsor

$\mathrm{Pn} ; \mathrm{Pn}+1=$ gaya horizontal yang bekerja pada sisi irisan

$\mathrm{Tn} ; \mathrm{Tn}+1=$ gaya tangesial pada sisi irisan

$\mathrm{N} \quad$ = gaya normal yang tegak lurus pada bidang longsor

$\mathrm{S} \quad=$ kekuatan geser yang bekerja sepanjang bidang longsor

$\alpha \quad=$ kemiringan bidang longsor 
GeoStudio 2007 merupakan software di bidang geoteknik yang dikembangkan di Kanada. Dalam menganalisa kestabilan lereng digunakan Slope/W yang menggunakan metode limit equilibrium (Rus, Suyadi, \& Munawir, 2015). Urutan menggunakan software ini adalah sebagai berikut:

1. Analisis kasus

2. Mengatur ruang kerja

3. Menentukan parameter yang diinput

4. Penggambaran stratifikasi lereng dan parameter - parameter analisis

Berdasarkan permasalahan yang diuraikan, maka penelitian ini akan menganalisis, menentukan faktor keamanan lereng dan mendesain penanggulangan longsoran pada ruas jalan Nimbontong Taja Lereh di Km 123+700.

Tujuan dari penelitian ini adalah dapat mengetahui faktor keamanan lereng dan mencari desain penanggulangan longsoran berdasarkan faktor keamanan lereng yang diperoleh dari analisis kestabilan lereng pada ruas jalan Nimbontong - Taja - Lereh di Km 123+700.

\section{Metode Penelitian}

Metode penelitian yang dipakai dalam penulisan ini adalah dengan cara mengumpulkan data yang berhubungan dengan perhitungan yaitu topografi dan parameter tanah. Teknik pengumpulan data menggunakan data primer dan sekunder. Data primer yaitu data yang diperoleh secara langsung di lapangan dengan survey lokasi, sedangkan data sekunder yaitu data yang diperoleh dari studi literatur/ sumber penelitian seperti instansi pemerintah, dan swasta.

Berdasarkan data penelitian, maka dapat dirincikan langkah - langkah yang akan diambil yaitu mengumpulkan informasi dan identifikasi masalah dalam hal ini stratifikasi penampang lereng, klasifikasi tanah berdasarkan data sondir dan berat jenis tanah melalui pendekatan, kemudian dilakukan analisa data dan perhitungan menggunakan program Geoslope untuk mengetahui kestabilan lereng lalu membuat kesimpulan dan saran sesuai analisa data perhitungan.

Analisa data dilakukan setelah semua data-data terkumpul dan analisa perhitungan disesuaikan dengan dasar teori yang ada.

\section{Hasil dan Pembahasan}

Berdasarkan data sondir yang diperoleh dan setelah dikorelasikan maka diketahuhi lapisan-lapisan tanah yang mempunyai jenis, sifat fisik dan sifat teknik sebagai berikut

Tabel 3

Sifat fisik dan sifat teknik lapisan tanah

\begin{tabular}{lccccl}
\hline & $\mathbf{N}$ & $\begin{array}{c}\gamma \\
\text { SPT }\end{array}$ & $\mathbf{K N}^{(\mathbf{o})}$ & $\begin{array}{c}\mathbf{C} \\
(\mathbf{K p a})\end{array}$ & \multicolumn{1}{c}{ Klasifikasi } \\
\hline Lapisan.1 & 0,42 & 18,00 & 1,60 & 12,50 & Lempung Lembek \\
\hline Lapisan.2 & 5,54 & 17,99 & 7,08 & 5,60 & Lempung Kelanauan \\
\hline
\end{tabular}




\begin{tabular}{lccccl}
\hline & $\mathbf{N}$ & $\begin{array}{c}\gamma \\
\text { SPT }\end{array}$ & $\boldsymbol{( K N / M}^{(\mathbf{o})}$ & $\begin{array}{c}\mathbf{C} \\
(\mathbf{K p a})\end{array}$ & \multicolumn{1}{c}{ Klasifikasi } \\
\hline Lapisan.3 & 13,14 & 16,65 & 6,75 & 6,10 & Lempung Kenyal \\
\hline Lapisan.4 & 18,78 & 18,27 & 7,03 & 5,50 & Pasir Kelanauan \\
\hline Lapisan.5 & 20,88 & 20,00 & 2,80 & 200,00 & Lempung Kenyal \\
\hline Lapisan.6 & 23,37 & 20,00 & 30,00 & 1,00 & Kerikil Pasir Lepas \\
\hline Lapisan.7 & 57,74 & 23,00 & 35,00 & 2,50 & Pasir Kerikil Padat \\
\hline
\end{tabular}

Setelah mendapatkan lapisan-lapisan tanah beserta jenis, sifat fisik dan tekniknya yang merupakan pengurutan lapisan tanah dari muka tanah sampai batas kedalaman penyelidikan, lapisan-lapisan tersebut diplotkan ke dalam gambar penampang melintang lereng yang diperoleh dari peta topografi sehingga menunjukkan bentuk stratifikasi lapisan-lapisan tersebut di dalam tanah.

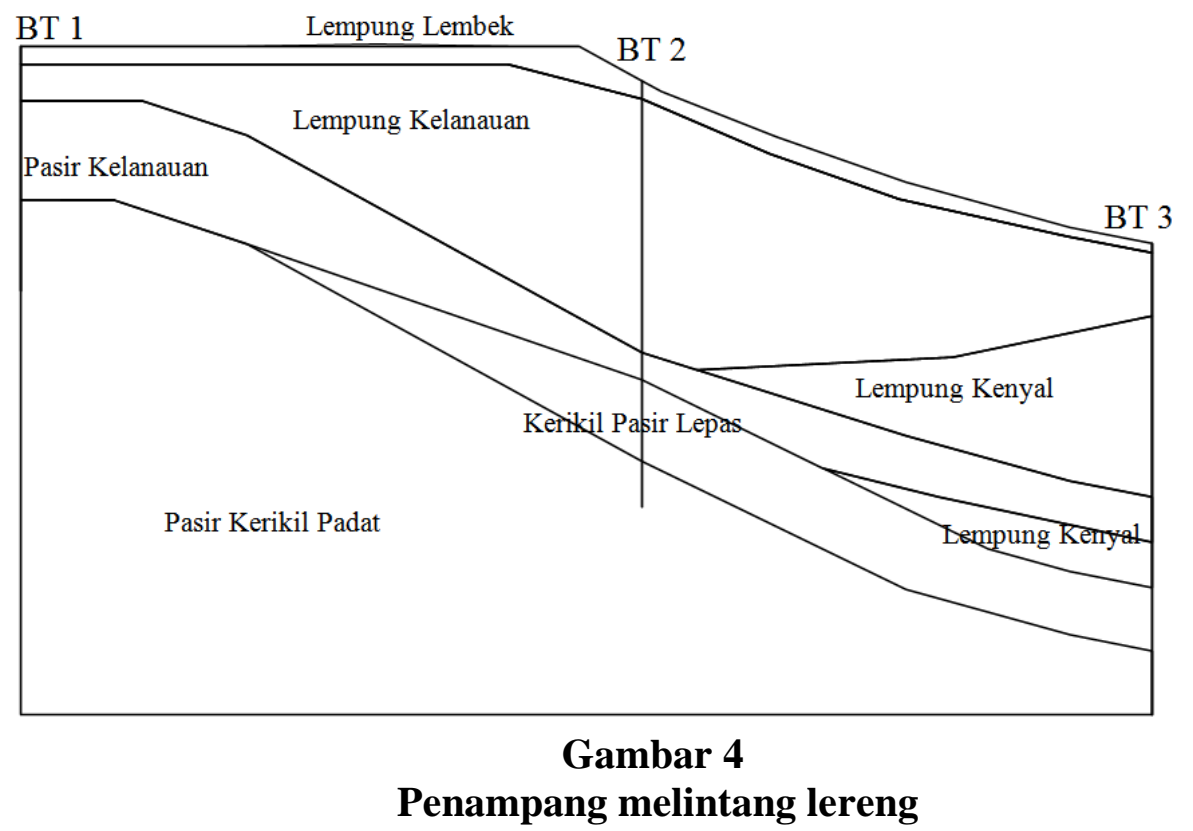

Kemudian setelah terbentuk stratifikasi penampang lereng, stratifikasi tersebut dimodelkan ke dalam program Geoslope dengan mengikuti lapisan-lapisan tanah beserta jenis, sifat fisik dan tekniknya yang ditampilkan sebagai berikut: 


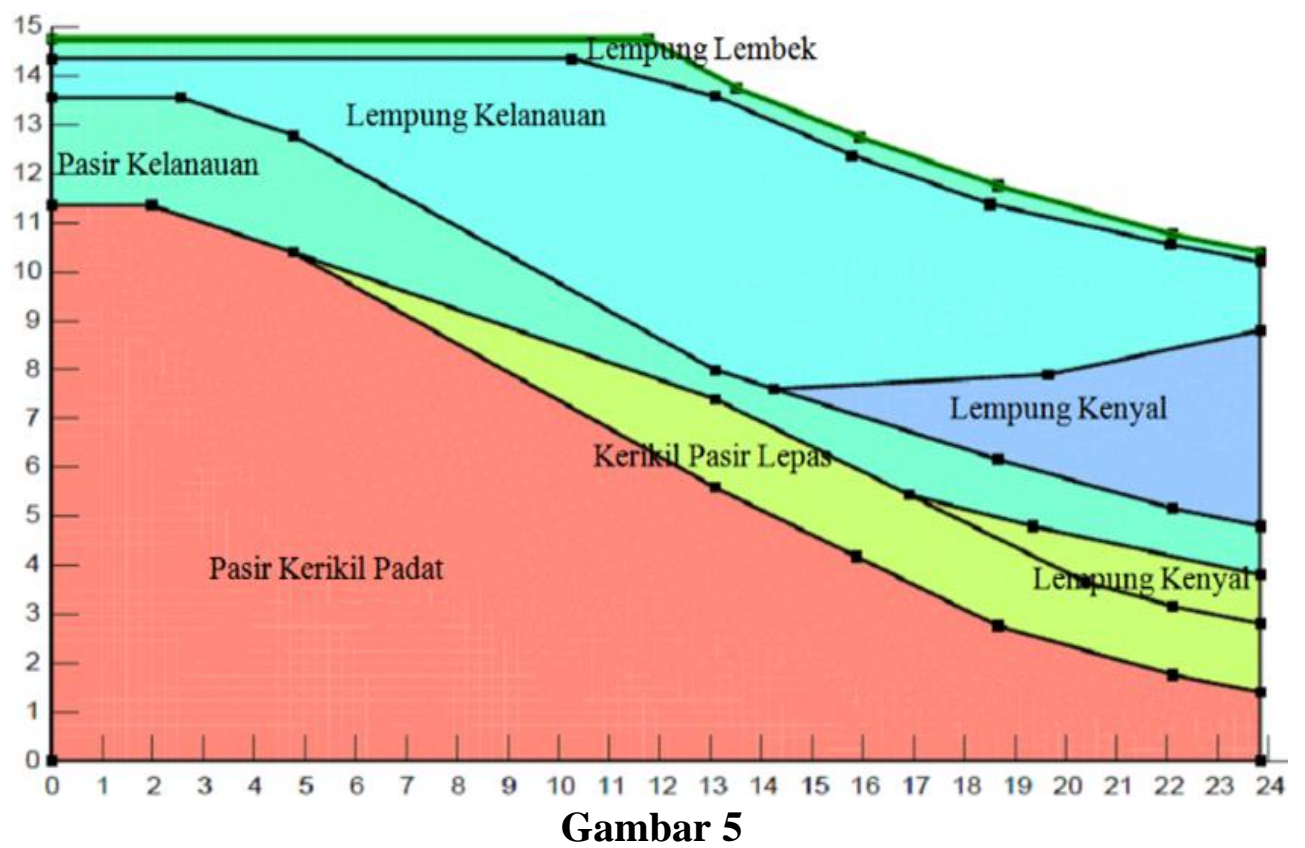

Stratifikasi penampang lereng

Pembebanan yang diperlukan pada analisis kestabilan lereng pada ruas jalan Nimbotong - Taja - Leheh STA 123+700 merupakan beban lalu lintas. Beban lalu lintas diambil sebesar $12 \mathrm{kPa}$ berdasarkan kelas jalan yaitu jalan kelas II. Analisis pada program Slope/W dilakukan dengan tiga macam kondisi yaitu:

Tabel 4

Analisis dengan kondisi asli

\begin{tabular}{lcc}
\hline Metode & Moment & Force \\
\hline Ordinary & 1,006 & - \\
\hline Bishop & 1,069 & - \\
\hline Janbu & - & 0,989 \\
\hline Morgenstern-Price & 1,068 & 1,068 \\
\hline
\end{tabular}

Tabel 5

Analisis dengan kondisi diberi beban jalan

\begin{tabular}{lcc}
\hline Metode & Moment & Force \\
\hline Ordinary & 1,006 & - \\
\hline Bishop & 1,099 & - \\
\hline Janbu & - & 0,954 \\
\hline Morgenstern-Price & 1,098 & 1,098
\end{tabular}

Tabel 6

Analisis dengan pembebanan dan tekanan air pori

\begin{tabular}{lcc}
\hline Metode & Moment & Force \\
\hline Ordinary & 0,699 & - \\
\hline
\end{tabular}




\begin{tabular}{lcc}
\hline Metode & Moment & Force \\
\hline Bishop & 0,812 & - \\
\hline Janbu & - & 0,697 \\
\hline Morgenstern-Price & 0,811 & 0,803 \\
\hline
\end{tabular}

\section{Kesimpulan}

Dari analisis yang telah dilakukan, dengan kondisi diberi beban jalan dan tekanan air pori maka dapat diambil kesimpulan bahwa lereng pada ruas jalan Nimbotong - Taja - Lereh Km 123+700 termasuk lereng yang kritis terhadap longsor karena faktor kemanan lereng berada dibawah 1,07. Faktor penyebab longsor yang menentukan adalah akibat tekanan air pori karena setelah dilakukan analisis menggunakan beban jalan sebesar $12 \mathrm{Kpa}$, hasil analisis menunjukkan faktor keamanan masih diatas 1,07. Perlu diadakan penelitian lebih lanjut guna mengetahui bagaimana cara penanganan longsor pada ruas jalan Nimbotong - Taja - Lereh Km 123+700. 


\section{BIBLIOGRAFI}

Akbari, Surya, \& Jaya, Zarqa. (2019). Desainjembatan Sungai Air Simpang Ii Kabupaten Ogan Ilir Provinsi Sumatatera Selatan. Politeknik Negeri Sriwijaya. repository. Google Scholar

Aprilia, Jesica, Muslim, Dicky, Zakaria, Zufialdi, \& Tedy, Osmon. (2019). Evaluasi Kestabilan Lereng Tambang Batubara Pit 'Xy'menggunakan Metode Kesetimbangan Batas Pt. Bukit Asam Tbk. Geoscience Journal, 3(3), 175-181. Google Scholar

Dewantanu, Panji, \& Taufiq, Muhammad. (2012). Studi Pengaruh Infiltrasi Air Hujan Terhadap Kestabilan Lereng Pada Kontruksi Timbunan Tanah. Fakultas Teknik Unissula. Repository Unissula. Google Scholar

Haribulan, Renhard, Gosal, Pierre H., \& Karongkong, Hendriek H. (2019). Kajian Kerentanan Fisik Bencana Longsor Di Kecamatan Tomohon Utara. Jurnal Spasial, 6(3), 714-724. Google Scholar

Kamil, Arifin, Poli, Hanny, \& Karongkong, Hendriek H. (2014). Kajian Pemanfaatan Lahan pada Daerah Rawan Longsor di Kecamatan Tikala Kota Manado. Sabua: Jurnal Lingkungan Binaan Dan Arsitektur, 6(2), 215-222. Google Scholar

Karapa, Enos, Harianto, Tri, Muhiddin, Achmad Bakri, \& Irmawaty, Rita. (2020). Uji Kuat Tarik Model Blok Tipe X Penopang Riprap untuk Perkuatan Lereng. Seminar Nasional Teknik Sipil X 2020. Repository Universitas Muhammadiyah Surakarta. Google Scholar

Muhammad, Budiman. (2012). Geologi dan Studi Kestabilan Lereng Daerah Dlingo dan Sekitarnya Kecamatan Dlingo Kabupaten Bantul Daerah Istimewa Yogyakarta. Repository UPN" Veteran" Yogyakarta. Google Scholar

Noor, Djauhari. (2014). Pengantar Mitigasi Bencana Geologi. Bogor : Deepublish. Google Scholar

Pradhana, Radhitya. (2018). Analisis Stabilitas Lereng Dengan Perkuatan Geotekstil (Studi Kasus: Bantaran Sungai Code, Kecamatan Jetis, Daerah Istimewa Yogyakarta) Analysis Of Slope Stability With Geotextile Reinforcement (Case Study: Code Riverbank, District Jetis, Special Region Of Yogyakarta). Google Scholar

Putri, Anak Agung Ayu Dwinta. (2019). Penerapan Metode Bercerita Menggunakan Media Audio-Visual untuk Meningkatkan Pemahaman Anak Usia Dini Mengenai Bencana Alam. Jurnal Pendidikan Anak Usia Dini Undiksha, 7(3), 246-250. Google Scholar

Rus, Tatag Yufitra, Suyadi, Widodo, \& Munawir, As'ad. (2015). Analisis Stabilitas Lereng Memakai Perkuatan Soil Nailing Dengan Bantuan Perangkat Lunak 
Slope/w (Studi Kasus Pada Sungai Parit Raya). Jurnal Mahasiswa Jurusan Teknik Sipil, 1(3), pp-995. Google Scholar

Sadikin, Dadan Ali, \& Komarudin, Komarudin. (2018). Studi Stabilitas Lereng Timbunan Jalan Terhadap Variasi Kemiringan. Jurnal Rekayasa Infrastruktur, 2(1), 1-10. Google Scholar

Sartika, Diana Destri, \& Yakin, Yuki Achmad. (2017). Analisis Stabilitas Lereng Tanah Berbutir Kasar dengan Uji Model Fisik. RekaRacana: Jurnal Teknil Sipil, 3(2), 70. Google Scholar

Sinarta, I. Nengah. (2013). Ancaman Tanah Longsor sebagai salah satu indikator dalam Pembangunan Infrastruktur berkelanjutan. Repository warmadewa. Google Scholar

Suwaryo, Putra Agina Widyaswara, \& Yuwono, Podo. (2017). Faktor-faktor yang mempengaruhi tingkat pengetahuan masyarakat dalam mitigasi bencana alam tanah longsor. Urecol, 305-314. Google Scholar

\section{Copyright holder:}

Alfian Adie Chandra (2021)

First publication right:

Syntax Idea

This article is licensed under:

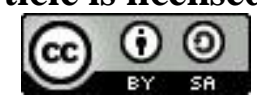

